\title{
Comparação entre os teores de óleos e graxas de escuma e lodo produzidos em estações de tratamento de esgoto da região metropolitana de Curitiba \\ Oil and grease comparison of scum and sludge produced in sewage treatment plants in Curitiba's metropolitan area

\author{
Data de entrada: \\ 19/09/2019 \\ $16 / 12 / 2019$
} \\ - Data de aprovação:
}

Bárbara Zanicotti Leite Ross ${ }^{1 *}$ | Fernanda Janaína Oliveira Gomes da Costa ${ }^{1}$ | Luana Maria Lotti Domingos ${ }^{2}$ | André Luiz de Faria' ${ }^{1}$ | Eduardo Sabino Pegorini'

DOI: https://doi.org/10.36659/dae.2021.029

ORCID ID

Ross BZL (D) https://orcid.org/0000-0003-1163-4001

Costa FJOG (D) https://orcid.org/0000-0002-2243-979X
Domingos LML (D) https://orcid.org/0000-0003-0390-8738

Faria AL (iD) https://orcid.org/0000-0001-9224-3912

Pegorini ES (D) https://orcid.org/0000-0001-5368-5611

\section{Resumo}

Os reatores UASBs são amplamente utilizados no Paraná para tratamento de esgotos domésticos e requerem gerenciamento adequado de lodo e escuma. A disposição da escuma em conjunto com lodo facilitaria a logística na Estação de Tratamento de Esgoto (ETE). A fim de avaliar a semelhança desses dois substratos, compararam-se os teores de óleos e graxas (O\&G) de 135 amostras de escumas e lodos de 8 ETEs de Curitiba e Região Metropolitana. Constatou-se que o valor médio de O\&G para o lodo de esgoto anaeróbio $(0,43 \%)$ é ligeiramente superior ao valor médio da escuma $(0,36 \%)$, porém essa diferença fica dentro do desvio padrão dos resultados. Ainda, o espaçamento diferenciado do gradeamento de cada ETE não interferiu na composição de $O \& G$ das escumas e lodos avaliados, enquanto o fato de operar muito acima da vazão de projeto pode contribuir com uma maior quantidade de $O \& G$ no lodo, assim como ETEs que operam em vazões abaixo das vazões de projeto possuem maior teor de $O \& G$ na escuma.

Palavras-chave: Reator UASB. Lodo. Escuma. Óleos e graxas.

\section{Abstract}

UASB reactors are largely used in Paraná in sewage treatment, the scum and the sludge formed require proper management. The scum disposal associated with the sludge would benefit Wastewater Treatment Plant (WWTP) practice operations. In order to evaluate how similar these two substrates of oil and grease (O\&G) are, the content of 135 scum and sludge samples was compared in 8 WWTP from Curitiba and its metropolitan area. It was found that the $0 \& G$ average value for sewage anaerobic sludge $(0.43 \%)$ is slightly higher than the average scum value $(0.36 \%)$, however the difference is within the standard results deviation. Moreover, the different spacing of the grid of each WWTP did not interfere in the O\&G composition of the evaluated scum and sludge, whereas the fact of being operated well above the project flow may contribute to a larger amount of O\&G in the sludge, as well as the WWTP being operated at flow rates below project flow have higher $O \& G$ content in the scum.

Keywords: UASB reactor. Sludge. Scum. Oil and grease.

\footnotetext{
${ }^{1}$ Companhia de Saneamento do Paraná - Curitiba - Paraná - Brasil.

2 Universidade Federal do Paraná (UFPR) - Curitiba - Paraná - Brasil.

* Autora correspondente: barbarazlasanepar.com.br.
} 


\section{INTRODUÇÃO}

Os reatores UASB são a terceira tecnologia mais utilizada em países da América Latina e Caribe, atendendo a $17 \%$ das plantas avaliadas, e em primeiro lugar encontram-se as lagoas de estabilização (43\%) (NOYOLA et al., 2012). Nos novos projetos de Estações de Tratamento de Esgotos (ETE) no Brasil, os UASBs aparecem como a alternativa mais empregada (CHERNICHARO, 2011). No Paraná, a tecnologia é utilizada desde 1979; em 2005 a companhia estadual de saneamento já operava mais de 300 reatores (JURGENSEN, 2005), número que cresceu ao longo destes anos.

Apesar das vantagens de consumir pouca energia e ocupar uma pequena área para implantação, os UASBs apresentam não só limitações quanto ao atendimento dos padrões de lançamento como também um sério problema operacional relacionado à formação de escuma (ROSS, 2015). A escuma pode ser definida como uma camada de materiais flutuantes que se desenvolve na superfície de reatores e pode aparecer no tratamento de águas residuárias tanto domésticas como industriais (SOUZA; AQUINO; CHERNICHARO, 2006). Apesar da carência de informação sobre essa temática, os problemas operacionais decorrentes da formação e do acúmulo de escuma nos reatores instalados em ETEs do Estado do Paraná foram relatados em 1984 (GOMES; ALVES; SKIBA, 2007). Seu acúmulo pode prejudicar o desempenho do sistema em termos de qualidade do efluente, ocasionar perdas de biogás e até mesmo o rompimento do separador trifásico dos reatores (ROSS, 2015), além de apresentar operação trabalhosa e insalubre para remoção.

Por conta da busca de melhorias no processo de tratamento de esgoto envolvendo reatores UASB, a necessidade de facilitar a remoção e encontrar opções de destino final mais adequadas para a escuma são elementos fortemente considerados nos fóruns técnicos das companhias de saneamento brasileiras.
Acreditava-se que o alto teor de óleos e graxas (O\&G) na escuma fosse o item de maior preocupação e também um empecilho na destinação final do material. Entretanto, por conta de diversos estudos atuais sobre o assunto, reconhece-se a grande parcela de lodo presente em sua composição. Por essa razão, a escuma produzida em diversos reatores UASB apresenta composição semelhante à do lodo de esgoto anaeróbio. De acordo com estudo realizado em três ETEs do Estado do Paraná, o teor de O\&G variou de 28 a $126 \mathrm{~g} / \mathrm{kg}$ de ST; essa variação pode ser decorrente de diferentes concentrações de $O \& G$ no esgoto afluente a cada uma das ETEs e o tempo de acúmulo da escuma antes da coleta para avaliação, uma vez que a escuma de uma das ETEs é acumulada por no máximo cinco dias, antes do descarte, enquanto nas outras duas o período de acúmulo pode atingir um mês. No presente estudo, o lodo apresentou teor de O\&G médio de $91 \mathrm{~g} / \mathrm{Kg}$ de ST, encontrando-se dentro da faixa de variação das escumas avaliadas. $O$ número de amostras avaliadas variou entre 4 e 5 para cada uma das ETEs (ROSS, 2015).

\section{OBJETIVO}

Este trabalho teve por objetivo comparar os teores de O\&G de escumas e lodos de diversas ETEs da Região Metropolitana de Curitiba (RMC), produzidos em reatores UASB tratando esgoto doméstico.

\section{METODOLOGIA}

As amostras foram coletadas em 8 ETEs, sendo 3 em Curitiba e 5 em sua Região Metropolitana, e as coletas ocorreram entre os meses de janeiro e maio de 2018. As ETEs foram codificadas com as letras de $\mathrm{A}$ a $\mathrm{H}$ para proteger a identidade original do local. A Tabela 1 possui características operacionais de cada ETE. 
Tabela 1- Características gerais das ETEs avaliadas.

\begin{tabular}{|c|c|c|c|c|c|c|c|}
\hline ETE & Localização & $\begin{array}{c}\text { Modelo de } \\
\text { reator UASB }\end{array}$ & $\begin{array}{c}\text { Número de } \\
\text { Reatores }\end{array}$ & $\begin{array}{c}\text { Vazão de } \\
\text { projeto (Qp) }\end{array}$ & $\begin{array}{c}\text { Vazão } \\
\text { atual (Qa) }\end{array}$ \\
\hline A & Curitiba & Retangular modificado & 6 & $420 \mathrm{~L} / \mathrm{s}$ & $450 \mathrm{~L} / \mathrm{s}$ & 107,14 \\
\hline B & Curitiba & Retangular modificado & 7 & $490 \mathrm{~L} / \mathrm{s}$ & $650 \mathrm{~L} / \mathrm{s}$ & 132,65 \\
\hline C & Curitiba & Retangular modificado & 6 & $420 \mathrm{~L} / \mathrm{s}$ & $500 \mathrm{~L} / \mathrm{s}$ & 119,05 \\
\hline D & Araucária & Retangular tradicional & 2 & $140 \mathrm{~L} / \mathrm{s}$ & $90 \mathrm{~L} / \mathrm{s}$ & 64,29 \\
\hline E & Araucária & Retangular tradicional & 1 & $60 \mathrm{~L} / \mathrm{s}$ & $40 \mathrm{~L} / \mathrm{s}$ & $25 \mathrm{~mm}$ \\
\hline F & Contenda & Retangular tradicional & 1 & $30 \mathrm{~L} / \mathrm{s}$ & $10 \mathrm{~L} / \mathrm{s}$ & 26,67 \\
\hline G & Fazenda Rio Grande & Retangularmodificado & 3 & $210 \mathrm{~L} / \mathrm{s}$ & $150 \mathrm{~L} / \mathrm{s}$ & 33,33 \\
\hline H & Lapa & Tronco Cônico & 3 & $180 \mathrm{~L} / \mathrm{s}$ & $50 \mathrm{~L} / \mathrm{s}$ & $20 \mathrm{~mm}$ \\
\hline
\end{tabular}

A fim de analisar os teores de $O \& G$ no lodo bruto e na escuma produzidos em reatores UASB, foram coletadas de maneira pontual 135 amostras, diferindo a forma para cada ETE de acor- do com as particularidades do local conforme exposto na Tabela 2, paralelamente foi realizada a determinação do teor de sólidos totais (ST) das amostras.

Tabela 2 - Forma de coleta de escuma e de lodo de esgoto anaeróbio nas ETEs avaliadas.

\begin{tabular}{|c|c|c|}
\hline ETE & Forma de coleta de escuma & Forma de coleta do lodo de esgoto \\
\hline A & $\begin{array}{l}\text { A ETE não possui acesso ao interior do gasômetro, sendo a escuma } \\
\text { coletada apenas na área de decantação dos UASBs }\end{array}$ & Tubulações de coleta de amostra diretamente de dentro do reator \\
\hline B & $\begin{array}{l}\text { A ETE não possui acesso ao interior do gasômetro, sendo a escuma } \\
\text { coletada apenas na área de decantação dos UASBs }\end{array}$ & Tubulações de coleta de amostra diretamente de dentro do reator. \\
\hline C & $\begin{array}{l}\text { A ETE não possui acesso ao interior do gasômetro, sendo a escuma } \\
\text { coletada apenas na área de decantação dos UASBs }\end{array}$ & Canaleta de descarte do lodo para o adensador \\
\hline $\mathrm{D}$ & $\begin{array}{l}\text { A não possui cortina defletora de escuma, sendo possível coletar a } \\
\text { mesma gerada apenas no interior do gasômetro }\end{array}$ & Tubulações de coleta de amostra diretamente de dentro do reator \\
\hline $\mathrm{E}$ & $\begin{array}{l}\text { A geração de escuma na área de decantação era inexpressiva ou } \\
\text { inexistente, sendo a escuma coletada apenas no interior do gasômetro }\end{array}$ & Tubulações de coleta de amostra diretamente de dentro do reator \\
\hline $\mathrm{F}$ & $\begin{array}{l}\text { A geração de escuma na área de decantação era inexpressiva ou } \\
\text { inexistente, sendo a escuma coletada apenas no interior do gasômetro }\end{array}$ & Canaleta de descarte do lodo para o leito de secagem \\
\hline G & $\begin{array}{l}\text { A ETE não possui acesso ao interior do gasômetro, sendo a escuma } \\
\text { coletada apenas na área de decantação dos UASBs }\end{array}$ & Tubulações de coleta de amostra diretamente de dentro do reator \\
\hline $\mathrm{H}$ & $\begin{array}{l}\text { A ETE possui acesso ao interior do gasômetro e possui cortina defletora } \\
\text { de escuma, sendo a escuma coletada nesses dois locais }\end{array}$ & $\begin{array}{l}\text { Por não existir acesso ao lodo antes do desaguamento, o mesmo foi } \\
\text { coletado nos leitos de secagem }\end{array}$ \\
\hline
\end{tabular}

As amostras foram armazenadas e analisadas de acordo com o Standard Methods for the Examination of Water and Wastewater (APHA, 2012) utilizando-se o método 2540 para o teor de ST e o método 5520 para o teor de O\&G.

\section{RESULTADOS E DISCUSSÕES}

Uma característica importante a ser destacada é o formato dos reatores UASBs de cada ETE. Entende-se que o formato construtivo influencia diretamente os fluxos hidráulicos do esgoto no interior do reator e assim interfere na formação de zonas mortas, mistura do lodo e formação de escuma. De acordo com a Tabela 1, apresentada anteriormente, tem-se as ETEs D, E e F com reatores denominados "modelo tradicional", as ETEs A, B, C e G com reatores denominados "modelo modificado" e a ETE H com um modelo tronco cônico (Fig. 1).

A Fig. 1 apresenta um esquema comparativo entre os reatores de modelo tradicional e modificado encontrados no presente estudo. Dentre as principais diferenças, que podem influenciar a formação e composição da escuma, tem-se a existência de uma passagem entre o interior do 
separador trifásico, ou gasômetro, e a área de decantação, ocorrendo comunicação entre essas duas áreas nos reatores modificados. Essa comunicação permitiu a coleta de escuma apenas na área de decantação nas ETEs que possuem reatores modificados, uma vez que a escuma da área de decantação é a mesma que a escuma presente no interior do gasômetro, e a coleta de escuma apenas no gasômetro nas ETEs que possuem reatores tradicionais. Na mesma Fig. 1 tem-se o modelo de reator UASB equivalente ao existente na ETE $H$.

(a)

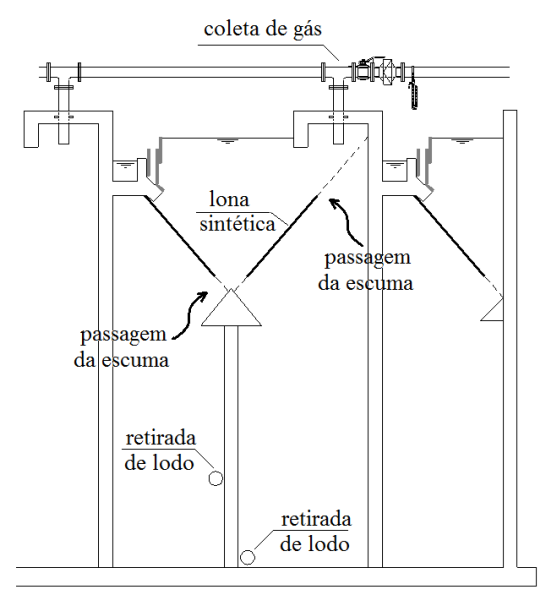

Reator UASB modificado

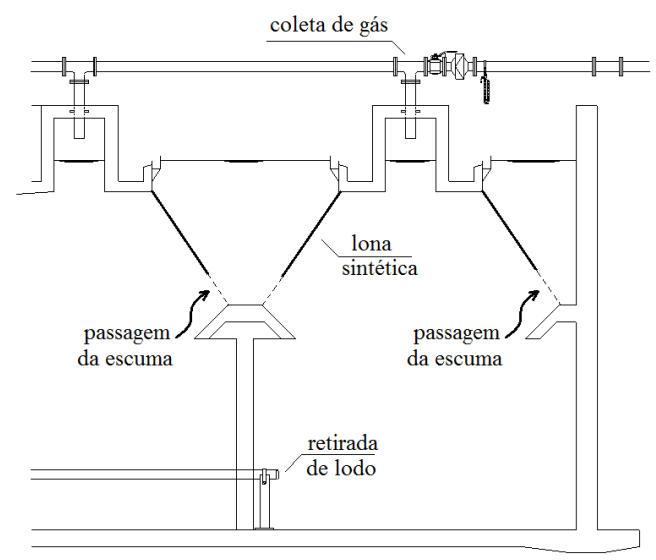

Reator UASB tradicional

(b)

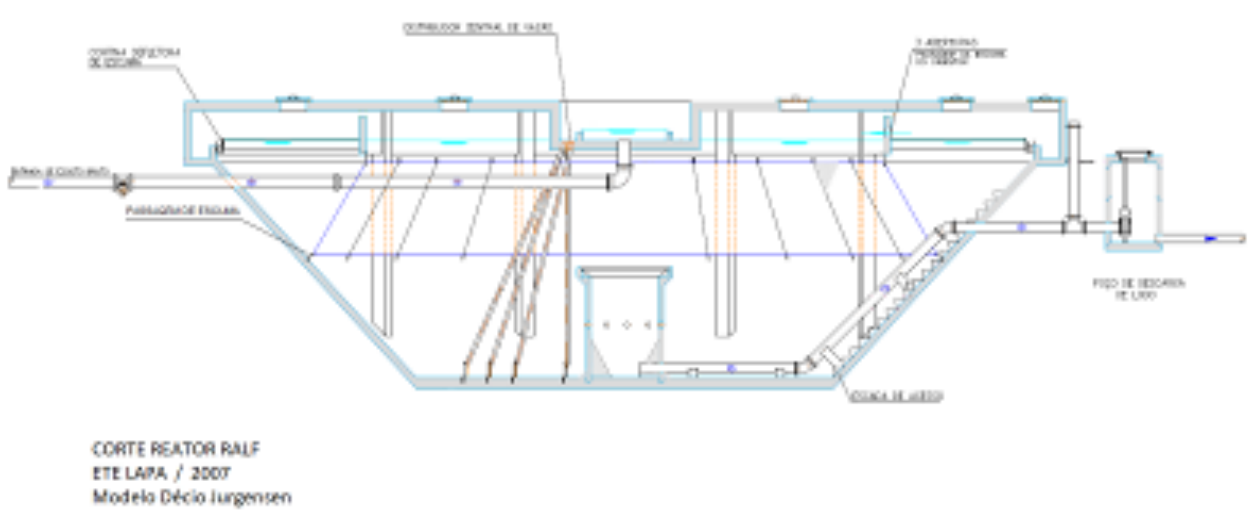

Figura 1 - Esquema comparativo entre os modelos de reatores UASBs: modificado (a), tradicional e tronco cônico (b).

A ETE D não possui cortina defletora na área de decantação, o que permite o livre escoamento da escuma acumulada nessa região; sendo assim, a mesma foi coletada apenas no interior do gasômetro. Não foram coletadas amostras no reator antigo, pois o mesmo está sendo reformado. 0 teor de sólidos nessa ETE variou de 2,72 \% a 50,4 $\%$ para a escuma e de $0,43 \%$ até $27,5 \%$ no lodo. $\mathrm{O}$ lodo foi coletado diretamente na tubulação de descarte (Fig. 2). 

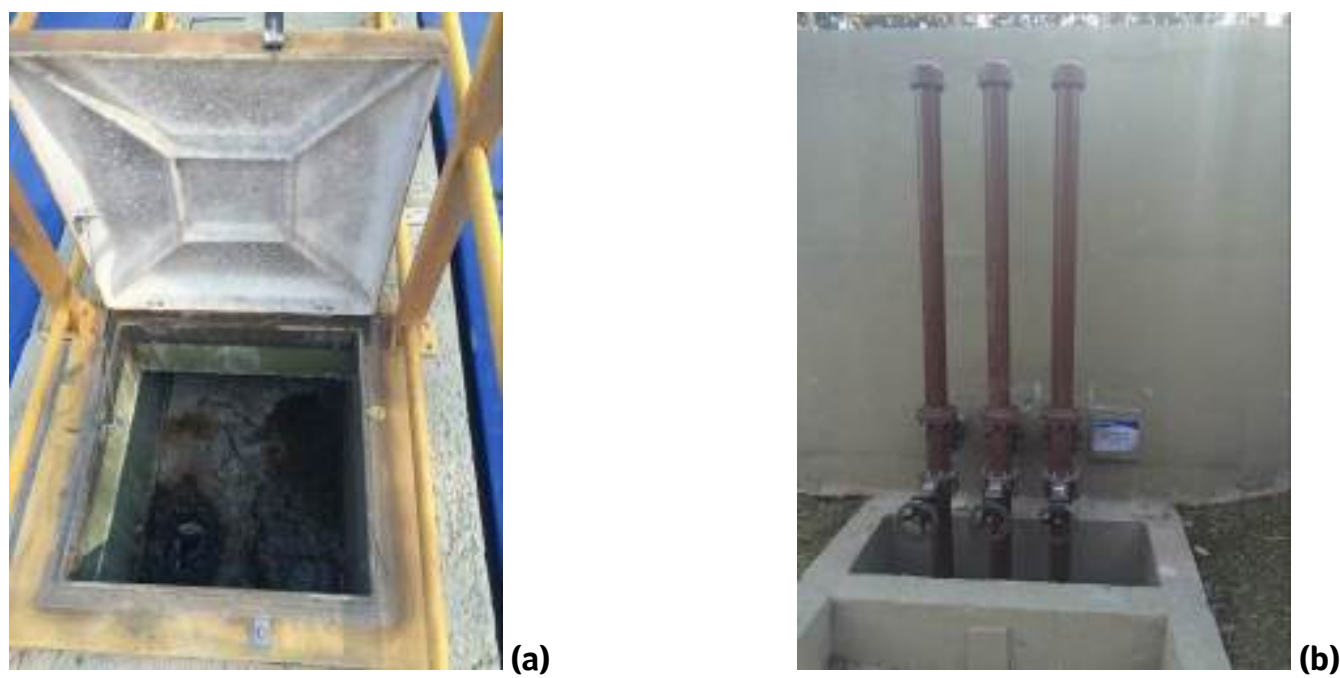

Figura 2 - Tampa e interior do gasômetro (a) e amostradores de lodo (b) da ETE D.

Na ETE B, por não haver abertura nos gasômetros, a escuma foi coletada apenas da área de decantação, e o lodo foi coletado nas tubulações de amostragem do mesmo. Os teores de ST encontrados variaram de $15,3 \%$ a $21,8 \%$ para a escuma e de 0,13 a $28,1 \%$ para o lodo.

O mesmo ocorreu com a ETE G, tendo a variação dos teores de ST da escuma de 0,44 a 22,7\% e de 0,14 a 36,7 para o lodo, e na ETE C, na qual

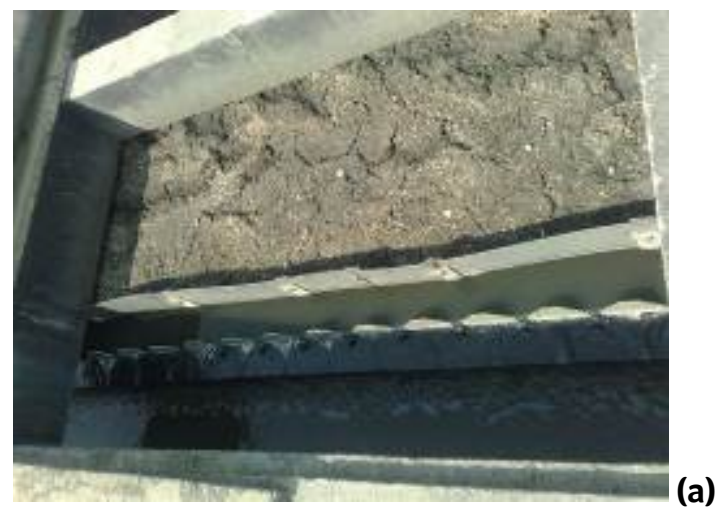

Figura 3 - Escuma espessa acumulada no decantador anaeróbio (a) e gasômetros fechados (b) na ETE A.

A ETE $F$ possui apenas um reator UASB de modelo tradicional. Acredita-se que por essa razão não houve muita formação de escuma na área de de-

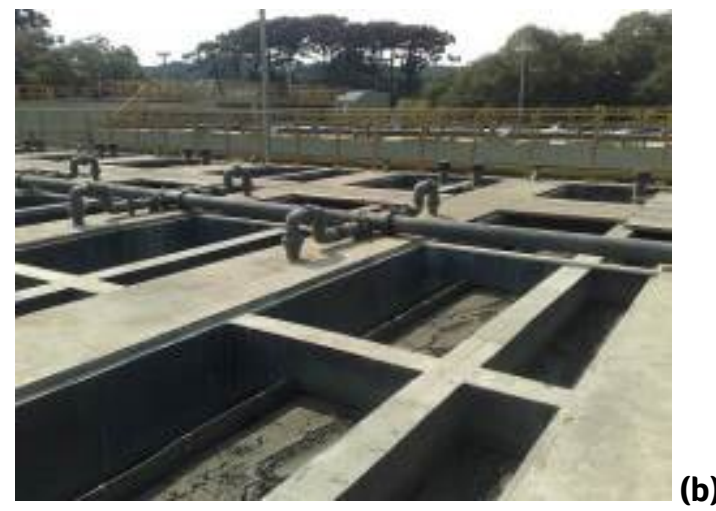

os teores de sólidos totais variaram de $3,27 \%$ a $34,5 \%$ para a escuma e de $0,37 \% 35,3 \%$ para o lodo. Na ETE A, a situação é similar às três ETEs previamente citadas, reatores modificados, sem acesso ao gasômetro. A escuma apresentou teores de ST entre $15,8 \%$ a $45,1 \%$ e o lodo de $0,3 \%$ a 25,5\% (Fig. 3). Os altos teores de ST na escuma da referida ETE comprovam o grande acúmulo observado visualmente de material.

(b) 
para o leito de secagem. Os valores de ST encontrados variaram de 3,31\% a 38,2\% para a escuma e de 2,17 a $26 \%$ para o lodo. $O$ projeto do reator da ETE E é semelhante ao da ETE F, por essa razão não houve

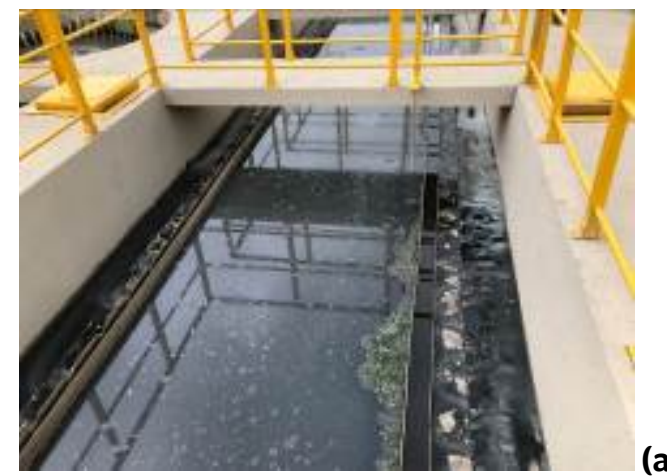

(a)

Figura 4 - Área de decantação (a) e gasômetros com tampa (b) na ETE F.

A ETE $\mathrm{H}$, diferentemente das demais, possui reator de formato tronco cônico, com acessos para coleta de escuma na área de decantação e no gasômetro (Fig. 5), porém o lodo só pode ser coletado no leito

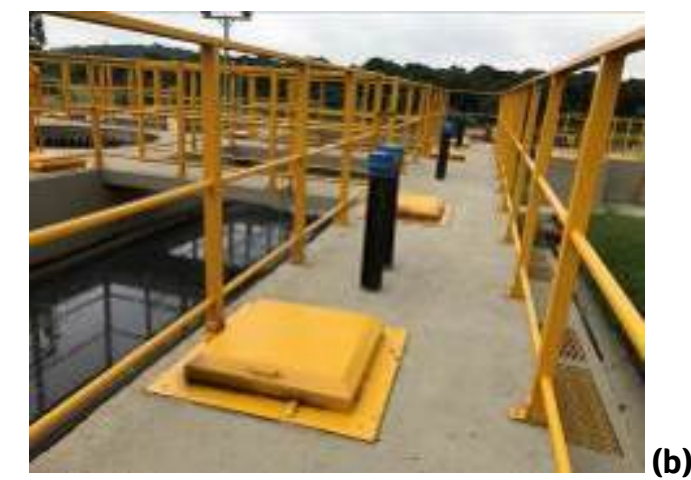

coleta de escuma na área de decantação, e o lodo foi coletado na tubulação de amostragem do mesmo. A escuma atingiu valores de ST entre $12,3 \%$ a $20 \%$, e o lodo variou de $0,32 \%$ a $39 \%$.

(b) de secagem. Os teores de sólidos da escuma variaram de $10,7 \%$ a $23,5 \%$, já os teores de ST do lodo, ficaram entre $16,8 \%$ e $60,3 \%$, valores esses adequados para lodo em processo de desaguamento.

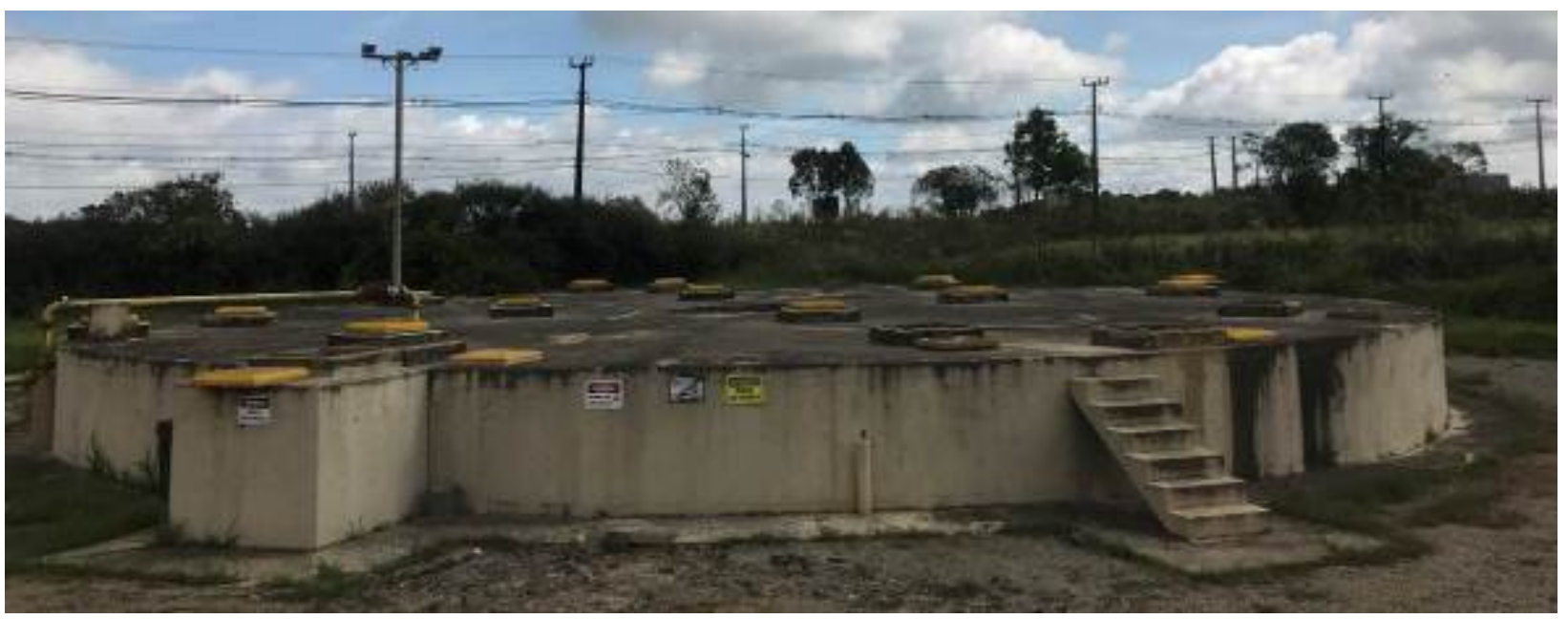

Figura 5 - Vista do reator da ETE H.

As Tabelas 3 e 4 sumarizam os resultados apresentados anteriormente, obtidos para a avalia- ção dos teores de O\&G e ST de escuma e lodo das ETEs avaliadas. 
Tabela 3 - Teores de óleos e graxas (\%) de lodo e escuma de ETEs da RMC.

\begin{tabular}{|c|c|c|c|}
\hline Valor & Amostras de lodo e escuma (N=131) & Só amostras de Escuma (N=68) & Só amostras de Lodo (N=63) \\
\hline Média & 0,39 & 0,36 & 0,43 \\
\hline Máximo & 7,90 & 6,10 & 7,90 \\
\hline Mínimo & 0,05 & 0,05 & 0,05 \\
\hline Desvio padrão & 0,96 & 0,79 & 1,12 \\
\hline
\end{tabular}

Obs.: $\mathrm{N}=$ número de amostras.

Tabela 4 - Teores de sólidos totais (\%) de lodo e escuma de ETEs da RMC.

\begin{tabular}{|c|c|c|c|}
\hline Valor & Amostras de lodo e escuma (N=135) & Só amostras de Escuma (N=70) & Só amostras de Lodo (N=65) \\
\hline Média & 14,96 & 16,75 & 13,04 \\
\hline Máximo & 60,3 & 50,4 & 60,3 \\
\hline Mínimo & 0,13 & 0,44 & 0,13 \\
\hline Desvio padrão & 10,81 & 7,85 & 13,07 \\
\hline
\end{tabular}

Obs.: $\mathrm{N}=$ número de amostras.

Com relação aos teores de $O \& G$, observa-se que o valor médio encontrado para o lodo de esgoto anaeróbio $(0,43 \%)$ é ligeiramente superior ao valor médio da escuma $(0,36 \%)$, porém essa diferença fica dentro do desvio padrão dos resultados. Além disso, a grande maioria dos resultados ficou abaixo de $1 \%$ de $O \& G$.

A semelhança entre resultados se repetiu com as amostras que foram avaliadas quanto ao teor de ST, tendo-se a média de $16,75 \%$ para escuma e 13,04\% para o lodo e um desvio padrão médio de $10,81 \%$.

A Fig. 6 (a) representa o gráfico de barras de erro para os resultados dos teores de O\&G das amostras de lodo e de escuma. Pode-se observar que os valores médios encontrados para escuma ficam englo- bados pelas barras de erro dos valores encontrados para o lodo, indicando a semelhança entre as amostras. Já a Fig. 6 (b) representa o gráfico de barras de erro para os resultados dos teores de ST das amostras de lodo e de escuma. Pode-se observar uma concentração um pouco superior para os resultados das escumas; salienta-se que esse parâmetro é fortemente dependente da forma de realização da coleta. Portanto, por meio dos dados obtidos foi possível verificar que não há diferença significativa entre os tratamentos, uma vez que os parâmetros avaliados de ST e O\&G apresentaram médias semeIhantes e ainda estão dentro, ou pelo menos muito próximos, da banda de confiança de $95 \%$ construída para todos os tratamentos em avaliação. (a)

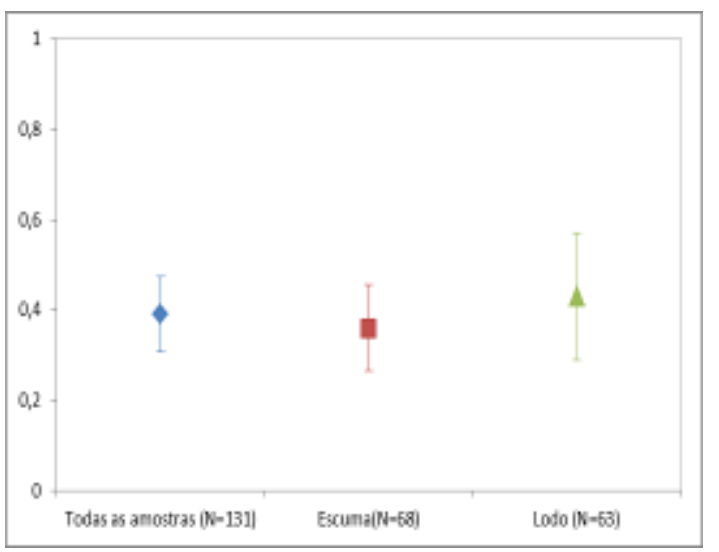

(b)

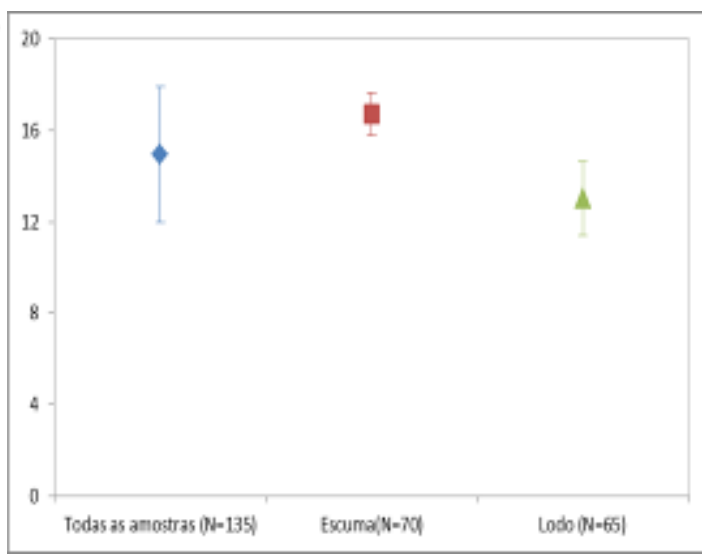

Figura 6 - Avaliação dos teores de O\&G (a) e ST (b) das amostras de lodo e de escuma de diversas ETEs da RMC ( $\mathrm{N}$ = número de amostras). 
As Fig. 7 e 8 apresentam o aspecto visual de algumas amostras, enquanto a Fig. 9 (a a h) contém os resultados dos teores de O\&G por ETE, considerando amostras de lodo e de escuma separadamente.

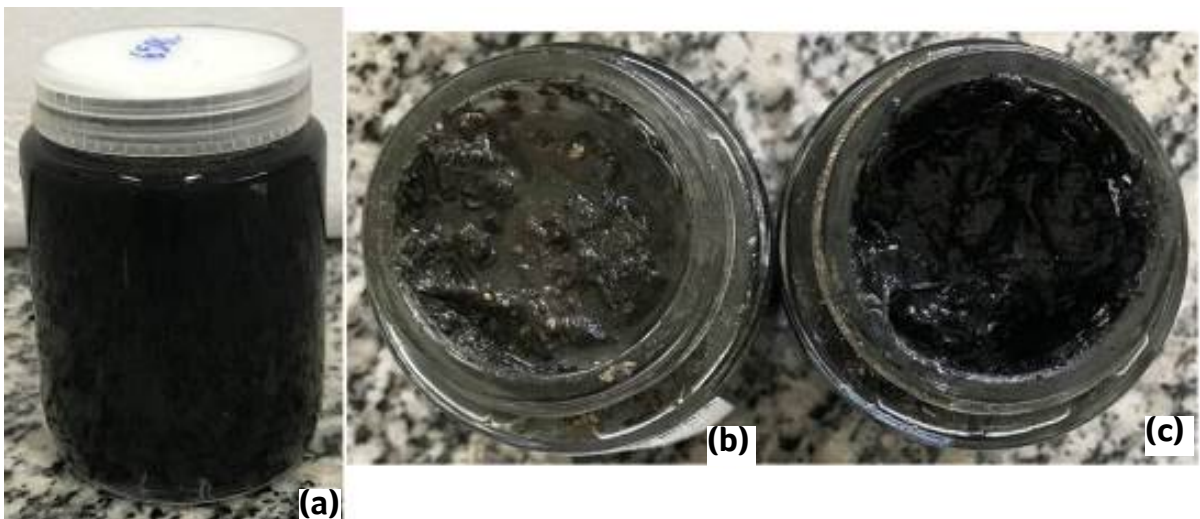

Figura 7 - Amostra de lodo da ETE D (a) e de escuma das ETEs A (b) e G (c).

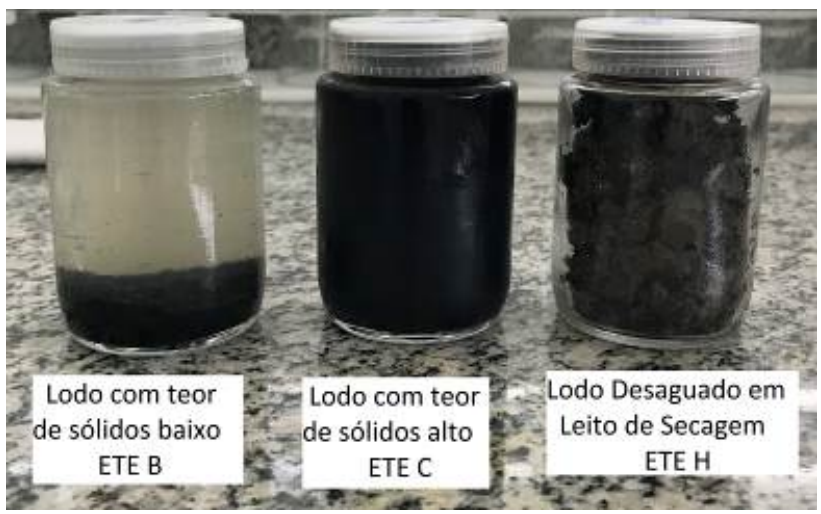

Figura 8 - Amostras de lodo nas ETEs B, C e H.
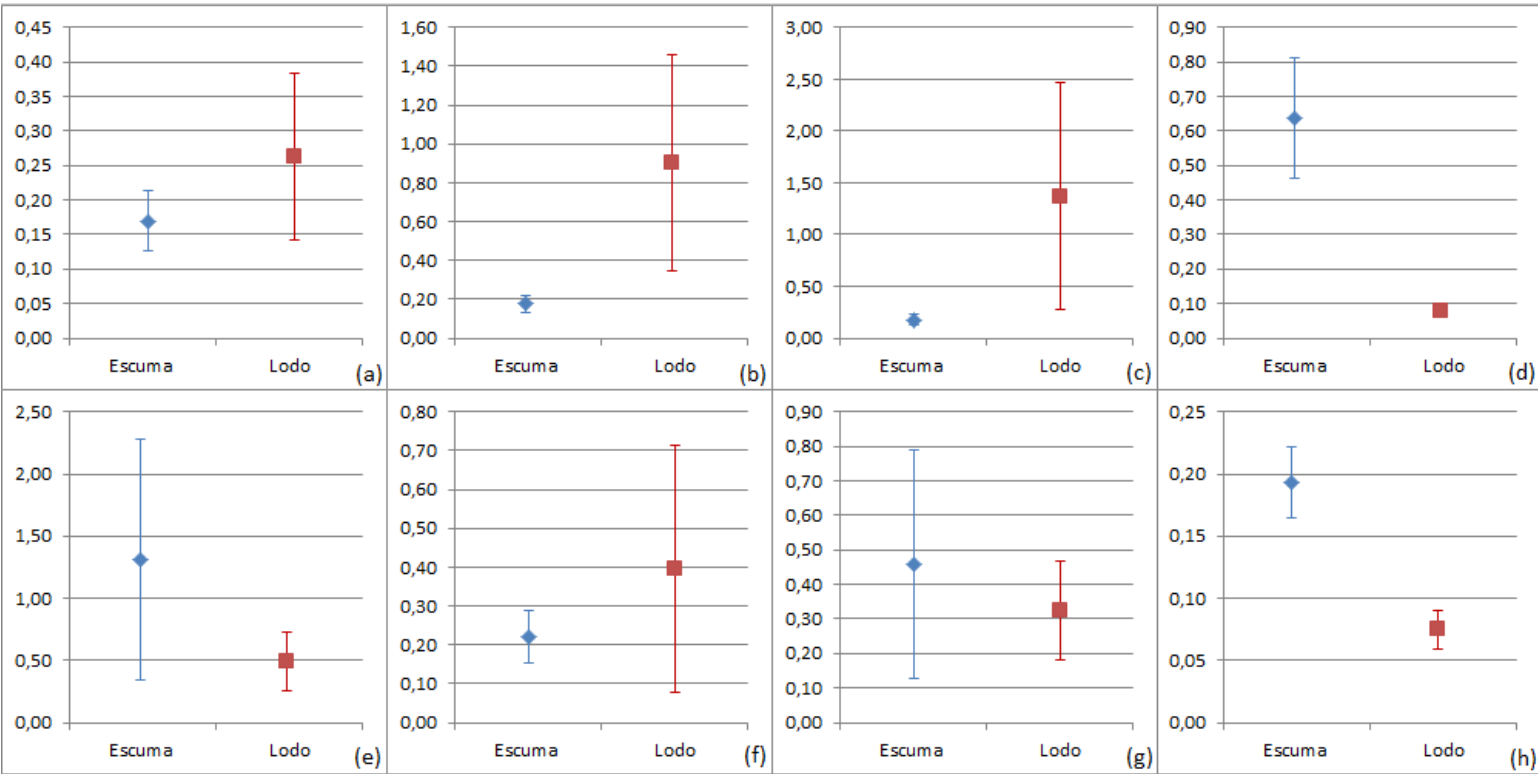

Figura 9 - Avaliação dos teores de O\&G das amostras de lodo e de escuma das ETEs A (a), B (b), C (c), D (d), E (e), F (f), $\mathrm{G}(\mathrm{g})$ e H (h) de Curitiba e Região Metropolitana. 
As ETEs D e H possuem lodo e escuma com teores diferenciados de O\&G, sendo os valores encontrados para a escuma levemente superiores aos valores encontrados para o lodo, mas em ambos os casos os teores são inferiores a $1 \%$. Na ETE $D$ o reator é do modelo tradicional e na ETE H é o tronco cônico e ambas estão operando bem abaixo da vazão de projeto, sendo $64 \%$ e $27 \%$ da capacidade, respectivamente, e também ambas possuem gradeamento mais grosseiro: 25 e 20 $\mathrm{mm}$. Em um estudo realizado na ETE Vassoural, da cidade de Guarapuava, Ross (2015) observou que, quando operado abaixo da vazão de projeto, ocorre uma transferência dos $O \& G$ do meio líquido para a escuma, situação semelhante à observada nos reatores das ETEs $\mathrm{D}$ e $\mathrm{H}$.

As ETEs B e $C$ possuem os teores de O\&G na escuma ligeiramente inferiores aos teores encontrados no lodo.

A ETE B está com a vazão $32 \%$ acima da capacidade regular, e a ETE C trata $20 \%$ a mais; am- bas possuem o reator modificado e gradeamento fino, $6 \mathrm{~mm}$. Mostrando-se na situação inversa à dos reatores das ETEs $\mathrm{D}$ e $\mathrm{H}$, na situação em que a vazão de operação está acima da vazão de projeto, favorece-se a permanência dos óleos de graxas no meio líquido e no lodo, não havendo tempo para a transferência dos compostos do esgoto para a escuma.

Para as demais ETEs, A, E, Fe G, pode-se dizer que não existe diferença significativa entre os teores de O\&G do lodo e escuma. Nos casos das ETEs A e $\mathrm{G}$ o reator é do modelo modificado; já as ETEs E e $F$ são reatores tradicionais, e as quatro estações estão operando ou abaixo ou próximo à capacidade de projeto, sendo $7 \%$ acima da vazão projetada no caso da ETE A, $67 \%, 33 \%$ e $71 \%$ da capacidade para as ETEs E, $F$ e $G$ respectivamente. Desse grupo, a ETE A é a única que possui gradeamento fino, $6 \mathrm{~mm}$.

Os resultados acima comentados e expostos na Fig. 9 encontram-se na Tabela 5.

Tabela 5 - Avaliação dos teores de O\&G e ST das amostras de lodo e de escuma das ETEs de Curitiba e Região Metropolitana.

\begin{tabular}{|c|c|c|c|c|c|c|c|c|}
\hline \multirow{3}{*}{ ETE } & \multicolumn{4}{|c|}{ O\&G (\%) } & \multicolumn{4}{|c|}{ ST (\%) } \\
\hline & \multicolumn{2}{|c|}{ Escuma } & \multicolumn{2}{|c|}{ Lodo } & \multicolumn{2}{|c|}{ Escuma } & \multicolumn{2}{|c|}{ Lodo } \\
\hline & média & desvio padrão & média & desvio padrão & média & desvio padrão & média & desvio padrão \\
\hline A & 0,17 & 0,11 & 0,26 & 0,32 & 22,23 & 11,29 & 7,52 & 8,5 \\
\hline B & 0,18 & 0,11 & 0,90 & 1,36 & 18,30 & 3,75 & 6,25 & 10,76 \\
\hline C & 0,18 & 0,14 & 1,37 & 2,90 & 16,22 & 9,21 & 10,45 & 12,03 \\
\hline $\mathrm{D}$ & 0,64 & 0,46 & 0,08 & 0,05 & 19,99 & 15,28 & 10,52 & 11,20 \\
\hline$E$ & 1,31 & 2,36 & 0,49 & 0,62 & 15,44 & 3,06 & 10,53 & 14,12 \\
\hline $\mathrm{F}$ & 0,22 & 0,16 & 0,39 & 0,84 & 17,38 & 10,72 & 8,32 & 8,31 \\
\hline $\mathrm{G}$ & 0,46 & 0,81 & 0,32 & 0,38 & 15,17 & 7,73 & 9,03 & 13,20 \\
\hline $\mathrm{H}$ & 0,19 & 0,14 & 0,07 & 0,06 & 14,78 & 2,89 & 26,32 & 11,32 \\
\hline
\end{tabular}

Com base no acima exposto, pode-se concluir que o gradeamento não interferiu na composição de O\&G das escumas e lodos avaliados, enquanto o fato de operar muito acima da vazão de projeto pode contribuir com uma maior quantidade de O\&G no lodo, assim como ETEs que operam em vazões abaixo das vazões de projeto possuem maior teor de $O \& G$ na escuma.
Ressalta-se que nesta pesquisa não foi avaliada a concentração de $O \& G$ no esgoto bruto, uma vez que o objetivo era apenas a comparação entre os teores encontrados na escuma e no lodo. Sendo assim, não é possível explicar o motivo pelo qual a escuma da ETE D possui mais O\&G do que a escuma da ETE E, já que ambas operam na faixa de $60 \%$ de sua capacidade. Possivelmente a 
concentração de O\&G afluente à ETE justificaria essa diferença entre as ETEs.

\subsection{Diferenciação de escuma do gasômetro e da área de decantação}

No caso da ETE H (Fig. 10), observou-se grande diferença visual entre as escumas geradas no interior do separador trifásico e na área de decantação. Essa diferença motivou a realização de coletas em separado de cada uma das escumas para compará-las com o lodo da mesma ETE (Fig. 11).

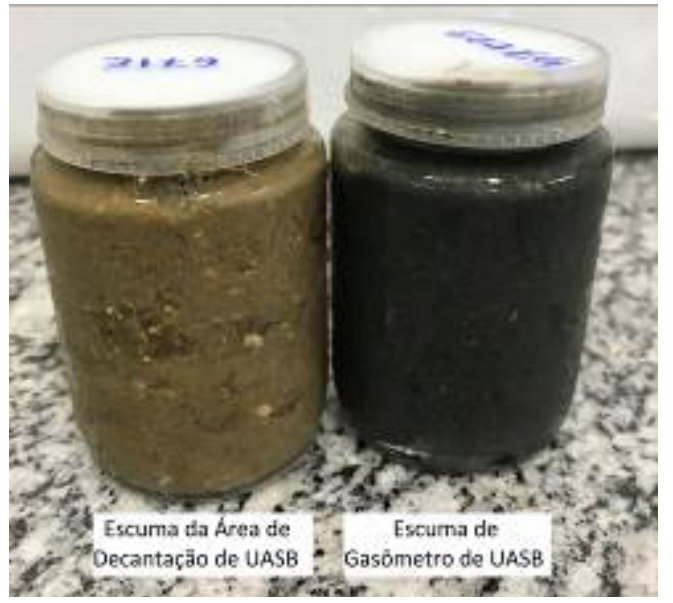

Figura 10 - Diferença do aspecto visual da escuma formada no interior do separador trifásico e na área de decantação da ETE H.

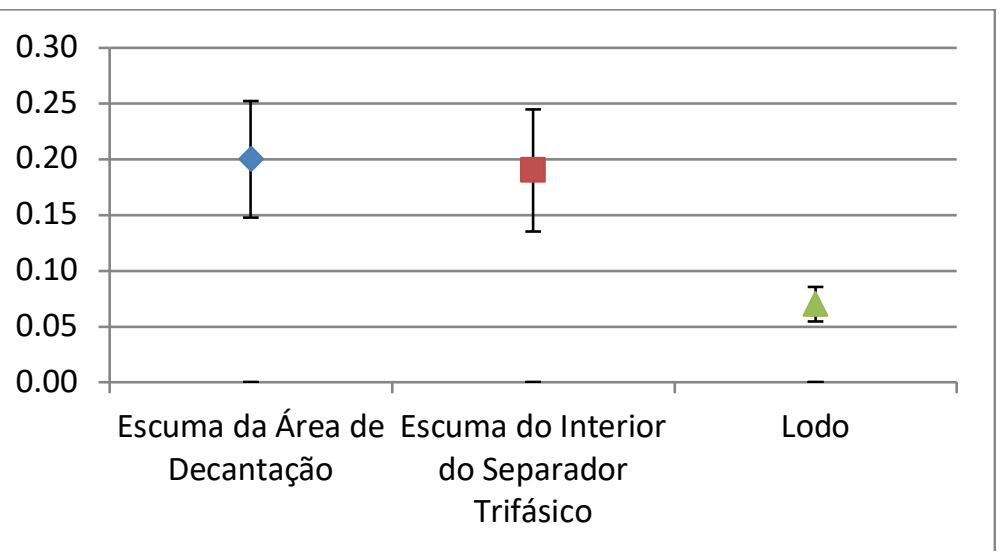

Figura 11 - Avaliação dos teores de O\&G (\%) das amostras de lodo e de escuma da área de decantação e do interior do separador trifásico da ETE $\mathrm{H}$.

Conforme apresentado na Fig. 11, não existe diferença significativa entre os valores médios das escumas produzidas no interior do separador trifásico $(0,19 \%)$ e na área de decantação $(0,20)$, porém o lodo produzido nessa ETE possui teores médios um pouco mais reduzidos $(0,07 \%)$. Quando observados os valores da Tabela 6, percebe-se que o valor máximo encontrado para o lodo, 0,23\% é muito próximo das médias encontradas para as escumas e que os valores máximos desse último substrato não ultrapassam $1 \%$ do total da amostra.
O teor de O\&G das escumas geradas no gasômetro e na área de decantação dos reatores da ETE H são bastante próximos e reduzidos, tendo-se 0,19\% para a escuma gerada no gasômetro e 0,20 \% para a escuma gerada na área de decantação. Com relação ao teor de $\mathrm{ST}$, encontraram-se os valores médios de 15,18 \% para a escuma do gasômetro e $13,93 \%$ para a escuma da área de decantação. Esses valores podem acarretar dificuldade no escoamento do material no momento da sua retirada. $\mathrm{Na}$ ETE H, a escuma é retirada por meio da sucção com mangotes de caminhão tipo "limpa-fossa". 
Tabela 6 - Teores de óleos e graxas e de sólidos totais (\%) de lodo e escuma da área de decantação e do interior do separador trifásico da ETE H.

\begin{tabular}{|c|c|c|c|c|c|c|}
\hline \multirow[b]{2}{*}{ Valor } & \multicolumn{3}{|c|}{ Óleos e Graxas (\%) } & \multicolumn{3}{|c|}{ Sólidos Totais (\%) } \\
\hline & $\begin{array}{l}\text { Lodo } \\
(N=15)\end{array}$ & $\begin{array}{c}\text { EG } \\
(N=9)\end{array}$ & $\begin{array}{c}E D \\
(N=9)\end{array}$ & $\begin{array}{l}\text { Lodo } \\
(\mathrm{N}=15)\end{array}$ & $\begin{array}{c}\text { EG } \\
(\mathrm{N}=9)\end{array}$ & $\begin{array}{c}\text { ED } \\
(\mathrm{N}=9)\end{array}$ \\
\hline Média & 0,07 & 0,19 & 0,20 & 26,32 & 15,18 & 13,93 \\
\hline Máximo & 0,23 & 0,53 & 0,45 & 60,30 & 17,20 & 23,50 \\
\hline Mínimo & 0,05 & 0,05 & 0,05 & 16,80 & 12,40 & 10,70 \\
\hline Desvio padrão & 0,06 & 0,16 & 0,16 & 11,32 & 1,39 & 3,78 \\
\hline
\end{tabular}

Obs.: $\mathrm{N}=$ número de amostras, $\mathrm{EG}$ = escuma do gasômetro e ED = escuma do decantador.

Com relação ao teor de sólidos totais (Tabela 6), percebe-se a baixa umidade, média de $26,32 \%$ de ST, e desvio padrão mais significativo de $11,32 \%$, nas amostras de lodo, fato que pode ser explicado devido ao fato de as amostras terem sido obtidas em leitos de secagem. Já as escumas não apresentaram muita variação no teor de sólidos, sendo o desvio padrão inferior a $4 \%$ nos dois casos.

\section{CONCLUSÕES}

Foram coletadas, em dias diferenciados, 135 amostras de lodo e de escuma em 8 ETEs de Curitiba e Região Metropolitana. As amostras tiveram o teor de O\&G e de ST avaliados.

O formato construtivo do reator UASB influencia diretamente nos fluxos hidráulicos do esgoto no interior do reator, e dessa forma interfere na formação de zonas mortas, mistura do lodo e formação de escuma. Dos reatores avaliados, 4 possuem o modelo tradicional de UASB, 3 são UASBs modificados e um é tronco cônico.

Com relação aos teores de O\&G, observa-se que o valor médio encontrado para o lodo de esgoto anaeróbio $(0,43 \%)$ é ligeiramente superior ao valor médio da escuma (0,36 \%), porém essa diferença fica dentro do desvio padrão dos resultados.

A grande maioria dos resultados de O\&G ficou abaixo de $1 \%$, tanto para escuma como para o lodo.
A semelhança entre resultados se repetiu com as amostras que foram avaliadas quanto ao teor de ST, tendo-se a média de $16,75 \%$ para escuma e $13,04 \%$ para o lodo e um desvio padrão médio de $10,81 \%$.

O gráfico de barras de erro elaborado para os resultados de O\&G indica que os valores médios encontrados para escuma ficam englobados pelas barras de erro dos valores médios encontrados para o lodo, comprovando a semelhança entre as amostras.

Já para o teor de ST, o gráfico de barras de erro evidencia uma concentração um pouco superior para os resultados das escumas, porém sem diferença significativa entre os tratamentos, muito próximos da banda de confiança de 95\% construída para todos os tratamentos em avaliação.

A diferença de espaçamento no gradeamento das ETEs avaliadas não interferiu na composição de $O \& G$ das escumas e lodos, enquanto o fato de operar muito acima da vazão de projeto pode contribuir com uma maior quantidade de $O \& G$ no lodo, assim como ETEs que operam em vazões abaixo das vazões de projeto possuem maior teor de O\&G na escuma.

A diferença visual entre as escumas geradas no interior do separador trifásico e na área de decantação de uma das ETEs não resultou em diferença significativa no teor de $O \& G$ das escumas produzidas no interior do separador trifásico 
$(0,19 \%)$ e na área de decantação $(0,20 \%)$, porém o lodo produzido nessa ETE possui teores um pouco mais reduzidos $(0,07 \%)$.

Com base nos resultados obtidos, entende-se que o lodo e a escuma coletados em 8 ETEs de Curitiba e Região Metropolitana não apresentam teores diferenciados de O\&G.

\section{AGRADECIMENTOS}

Os autores agradecem à toda equipe da Sanepar, em especial aos técnicos da Gerência de Tratamento de Esgoto (GTESG) e Gerência de Pesquisa e Inovação (GPIN) pelo apoio e contribuições no desenvolvimento deste trabalho.

\section{CONTRIBUIÇÃO DOS AUTORES}

Conceitualização: Ross BZL, Costa FJOG, Pegorini ES; Metodologia: Ross BZL, Domingos LML, Faria AL; Investigação: Ross BZL,Domingos LML, Faria AL; Redação Primeira Versão: Ross BZL,Costa FJOG, Domingos LML, Pegorini ES; Redação, Revisão \& Edição: Ross BZL, Costa FJOG.

\section{REFERÊNCIAS}

APHA (American Public Health Association); AWWA (American Water Works Association); WEF (Water Environment Federation) Standard methods for examination of water and wastewater, 22. ed. Washington: Publication Office American Public Health Association, 2012.

CHERNICHARO, C.A.L. Reatores Anaeróbios. Belo Horizonte, MG: Departamento de Engenharia Sanitária e Ambiental - UFMG, 2011.380p.

GOMES, C.S.; ALVES, H.B.; SQQUIBA, L.M. Escumas como pesadelos dos tratamentos RALF e UASB para esgotos sanitários. In: CONGRESSO BRASILEIRO DE ENGENHARIA SANITÁRIA E AMBIENTAL, 24, 2007, Belo Horizonte. Anais... ABES, 2007. 1 CD-ROM.

JURGENSEN, D. A experiência no tratamento de esgotos na Sanepar. In: SEMINÁRIO SOBRE TRATAMENTO DE ESGOTO, 2005, Curitiba. Anais... Curitiba: SANEPAR, 2005. 1 CD-ROM.

NOYOLA, A.R.; PADILLA-RIVERA, A.; MORGAN-SAGASTUME, J.M.; GÜERECA, L.P.; HERNÁNDEZ-PADILLA, F. Typology of municipal wastewater treatment technologies in Latin America. Clean-Soil, Air Water, v. 40 (9), p. 926 - 932, 2012. https://doi.org/10.1002/ clen.201100707

ROSS, B.Z.L. Escuma de reatores anaeróbios tratando esgotos domésticos em escala real: produção, caracterização e proposição de parâmetros para seu gerenciamento. Tese (Doutorado em Engenharia de Recursos Hídricos e Ambiental), UFPR, Curitiba, 2015, 163p.

SOUZA, C.L.; AQUINO, S.F.; CHERNICHARO, C.A.L. Production and characterization of scum and its role in odor control in UASB reactors treating domestic wastewater. Water Science \& Technology, v. 54, p. 201-208, 2006. https://doi.org/10.2166/wst.2006.745 